University of Wollongong

Research Online

Faculty of Business - Papers (Archive)

Faculty of Business and Law

$1-1-2019$

A critique of prospect theory and framing with particular reference to consumer decisions

John R. Rossiter

University of Wollongong, Charles Sturt University, jrossite@uow.edu.au

Follow this and additional works at: https://ro.uow.edu.au/buspapers

Part of the Business Commons

Research Online is the open access institutional repository for the University of Wollongong. For further information contact the UOW Library: research-pubs@uow.edu.au 


\title{
A critique of prospect theory and framing with particular reference to consumer decisions
}

\begin{abstract}
Prospect theory is criticized in this article for being borrowed from psychology without appropriate acknowledgement, for requiring mathematical calculations that are beyond the average person, for not investigating information processing during prospect theory choices, and for lacking application to realworld decisions-such as important product and service choices made by consumers. Further criticism is leveled at the prospect theory-derived technique known as "framing," which is based on one-sided presentation of information and would be unethical in most consumer behavior situations.

\section{Disciplines}

Business

\section{Publication Details}

Rossiter, J. R. (2019). A critique of prospect theory and framing with particular reference to consumer decisions. Journal of Consumer Behaviour: an international research review, 18 (5), 399-405.
\end{abstract}




\title{
A critique of prospect theory and framing with particular reference to consumer decisions
}

\author{
John R. Rossiter ${ }^{12}$ \\ ${ }^{1}$ Faculty of Business, University of Wollongong, NSW, Australia \\ ${ }^{2}$ School of Psychology, Charles Sturt University, NSW, Australia \\ Correspondence: Professor John R. Rossiter, Level 2, Mike Codd Building, Innovation Campus, \\ University of Wollongong, Wollongong NSW 2522, Australia. Email: \\ john_rossiter@uow.edu.au
}

August 23, 2019

\section{Author biography}

John R. Rossiter is honorary professorial fellow in the Faculty of Business at the University of Wollongong and adjunct research professor of psychology in the School of Psychology at Charles Sturt University. He is known internationally for the Rossiter and Percy advertising management textbooks, and for his invention of the multiple award-winning C-OAR-SE measurement procedure. John has authored or co-authored 10 books and published more than 90 journal articles over his career. John Rossiter's contribution to teaching and research on advertising and consumer behavior was recognized with his election in 2015 as a Member of the Order of Australia (AM). 


\title{
A critique of prospect theory and framing with particular reference to consumer decisions
}

\section{Keywords}

prospect theory, framing, real-world decision making

\begin{abstract}
Prospect theory is criticized in this article for being borrowed from psychology without appropriate acknowledgement, for requiring mathematical calculations that are beyond the average person, for not investigating information processing during prospect theory choices, and for lacking application to real-world decisions - such as important product and service choices made by consumers. Further criticism is leveled at the prospect theory-derived technique known as "framing," which is based on one-sided presentation of information and would be unethical in most consumer behavior situations.
\end{abstract}




\section{INTRODUCTION}

This article criticizes Kahneman and Tversky’s (1979; Tversky and Kahneman, 1981, 1992) prospect theory, as well as the prospect theory-derived technique known as framing. Criticism of prospect theory will undoubtedly be seen as controversial given its exalted standing in the social sciences. Daniel Kahneman was awarded the 2002 Nobel Prize for Economics largely on the basis of his co-invention of prospect theory, noting that the Nobel can be awarded only to living recipients and co-inventor Amos Tversky unfortunately died earlier. Kahneman and Tversky's 1979 version of prospect theory - it was modified substantially in the 1992 article by Tversky and Kahneman but this modification complicates the theory considerably and has been largely ignored - is cited in most psychology textbooks as an accepted principle of decision-making, and the associated concept of message framing, introduced in Tversky and Kahneman's famous illustration of the positive vs. negative framing of the "Asian disease problem," published in Science, is the leading example of prospect theory as it applies to decision-making in social dilemmas. In marketing, prospect theory’s principles of decisionmaking have been accepted as virtual axioms of consumer behavior (see, e.g., Mittal, Holbrook, Beatty, Raghubir, \& Woodside, 2008; Morales, Amir, \& Lee, 2017); and framing has been accepted as a legitimate persuasion technique and used in a number of consumer experiments (e.g., Donovan \& Jalleh, 1999; Janiszewski, Silk, \& Cooke, 2003). No one in the social sciences, to the present author's knowledge, has comprehensively questioned prospect theory, and no article critical of the framing effect could be found.

A brief overview of prospect theory and framing will be helpful in setting up the present article. A "prospect" is simply a proposed course of action presented together with its estimated chance (or probability, mathematically speaking) of achieving a particular outcome, where the outcome is considered to be either a gain or a loss. Prospect theory attracted attention because it offers an alternative to the classical economic theory of decision-making based on expected utility. Expected-utility theory assumes that the decision maker will judge a prospective loss, such as the prospect of losing $\$ 50$, as just as bad as a prospective gain of the same amount will be judged to be good, such as the prospect of winning $\$ 50$ - in other words, the decision maker is assumed to weight gains and losses equally. Prospect theory, on the other hand, postulates that "losses loom larger than gains" (Tversky \& Kahneman, 1992, p. 298) and specifically that losses carry about double the weight of gains. For example, prospect theory predicts that it would take a prospective gain of $\$ 100$, or twice the amount, to offset a prospective loss of $\$ 50$ (see Tversky \& Kahneman, 1992, p. 310). Prospect theory, therefore, is based on the assumption that decision makers are characteristically "loss averse" in choosing between prospects.

By combining the idea of loss aversion with the concept of perceived risk, Kahneman and Tversky (1979) formulated two prospect theory principles which they called the "certainty effect for gains" and the "possibility effect for losses," with the latter also known as the "probabilistic effect for losses." The certainty effect for gains predicts that the decision maker will choose an apparently certain gain over an apparently risky gain even though the two prospects have equal expected value; for instance, winning a sure \$50 is likely to be preferred over a 50\% chance of winning \$100. The probabilistic effect for losses predicts the opposite: that the decision maker will choose an apparently risky loss (risky in the sense of taking a gamble) over an apparently certain loss of equal expected value; for instance, a gamble of a 50\% chance of losing $\$ 100$ 
should be preferred over having to forfeit $\$ 50$ outright. Note that expected-utility theory says that when the expected values of the prospects are equal, as they are in these two examples, no rational choice can be made.

Shortly after Kahneman and Tversky’s (1979) article introducing prospect theory was published, Tversky and Kahneman (1981) proposed a derivative of the theory which they called the framing effect - a problem-presentation technique which is supposed to induce biased judgments and thus influence decisions. Framing concerns only those prospects that have both a potential gain and a potential loss associated with them - so-called mixed prospects A prospect is said to be "positively framed" if it mentions only the expected gain; whereas a prospect is said to be "negatively framed" if it mentions only the expected loss. In keeping with the certainty effect for gains, the decision maker when presented with a pair of positively framed prospects of equal expected value is predicted to choose the more certain prospect; whereas in keeping with the probabilistic effect for losses, the decision maker presented with a pair of negatively framed prospects of equal expected value is predicted to choose the more probabilistic prospect.

In the main part of the present article, the author criticizes prospect theory for being unoriginal, unproven, and most of all for lacking application to complex real-world decisions, particularly to those that consumer behaviorists would call high-involvement decisions. In the second part of the article, the author turns critical attention to framing, arguing that positive framing is unethical in high-involvement consumer marketing and negative framing is unethical in social marketing. In the last part, the author points out that consumer behavior theorists have contributed much more to the understanding of decision-making than have prospect theorists.

\section{A CRITIQUE OF PROSPECT THEORY}

\subsection{Prospect theory is unoriginal}

Prospect theory depends entirely on the concept of loss aversion. Not only is the idea that decision makers weigh losses more heavily than equivalent gains an illustration of loss aversion but so too are the two main prospect theory principles. The "certainty effect for gains" can be seen as following from loss aversion in that decision-makers see a risky gain as a potential loss, as expressed in the proverb "a bird in the hand is worth two in the bush." The "probabilistic effect for losses" can be seen as following from loss aversion in that decisionmakers are averse to subjecting themselves to an apparently certain loss and will proverbially "grasp at straws" or take any chance in the hope of avoiding it. Kahneman and Tversky imply that they invented the idea of loss aversion (see especially Tversky \& Kahneman, 1992, p. 298) but in fact it has much earlier roots which they failed to acknowledge. Specifically, its roots are in the psychology of perception and in learning theory.

What Kahneman and Tversky call loss aversion has long been known in the perception literature as the "negativity bias" (for a comprehensive historical review, see Baumeister, Bratslavsky, Finkenauer, \& Vohs, 2001; and see March, Gaertner, \& Olson, 2017, for a recent

experimental demonstration). Everyone learns almost from birth that it pays off behaviorally to be more perceptually sensitive to negative stimuli than to positive stimuli (for a comprehensive historical review, see Vaish, Grossmann, \& Woodward, 2008). The universal tendency to 
overweigh negative stimuli - "losses loom larger than gains" - therefore cannot be claimed to be an invention of prospect theory.

Loss aversion, also, has long been known in psychological learning theory as the principle that punishment, a "loss" in prospect theory terms, is more effective in changing behavior than is reward, a "gain" in prospect theory terms. Evidence for this asymmetry of punishment and reward dates back to well before Kahneman and Tversky formulated prospect theory (for the best early account, see Estes, 1944; and for a recent account see Domjan, 2018). Punishment is more effective than reward because it works much more quickly and permanently - often in a single trial, such as with the "fingers on a hot stove" phenomenon. Reward, on the other hand, works only after repeated trials, and the newly learned response is easily changed by the promise of a larger reward elsewhere, as in the "grass is always greener" proverb. It therefore follows from learning theory in psychology that people would prefer sure and immediate rewards over uncertain future rewards and would prefer the chance of avoiding punishment to the certainty of receiving punishment. This, of course, is a predating explanation of what Kahneman and Tversky referred to as the "certainty effect for gains" and the "probabilistic effect for losses."

The implication of all this is that Kahneman and Tversky borrowed from psychology perception and learning theory - without appropriate acknowledgement. While falsely claimed originality is not good scientific practice, it does not actually invalidate prospect theory. For this we turn to the next two criticisms.

\subsection{Prospect theory problems require unjustly high mathematical ability}

Kahneman and Tversky (1979) tested their prospect theory with a series of mathematical problems that required high mathematical ability to solve. The first three prospect theory problems that Kahneman and Tversky used in their article are reproduced in the present Table 1. It can be seen that the problems are difficult: they require a knowledge of probability, a knowledge of the expected value formula in which you have to multiply probability by value, and the ability to do so mentally.

Table 1 about here

This last requirement is crucial. The subjects in Kahneman and Tversky’s (1979) experiments were students and faculty members at leading universities, who can be presumed to have higher than average mathematical ability. However, even these highly educated individuals would have difficulty with Kahneman and Tversky's prospect theory problems. National statistics from the U.S. Department of Education (cited in Wikipedia 2017a, b; see also Siegler \& Lortie-Forgues, 2017) reveal that most American adults, even those very highly educated such as medical doctors, have appallingly low levels of computational competence - especially when it comes to multiplying by fractions, proportions, or probabilities as is required for making prospect theory choices. For most people, therefore, a lack of math literacy means that probabilistic prospect statements will not be interpreted as intended.

\subsection{Failure to measure information processing}

Failure to find out how the respondents actually did process each prospect - did they compute the expected value of the prospect, for example? - and how they made their choices between the paired prospects is a major deficiency of all the prospect theory experiments, 
including Kahneman and Tversky’s (1979) experiments with monetary decisions and Tversky and Kahneman's (1981) “framing effect” experiment critiqued in the second part of the present article.

Without an information-processing check, prospect theory remains speculative and unproven, as argued in an excellent review of decision-making research by Johnson, ShulteMecklenbeck, and Willemsen (2008). Only by using the "think aloud" verbal protocol method originated by Simon (1957) can light be shed on each individual's information processing in prospect theory-type problems. Researchers such as such as Bettman (1970) and Russo, Johnson, and Stephens (1989) have used this method to gain insights into consumer information processing but unfortunately it is little used today, perhaps because of the arduous work required for data collection and coding. Quite wrongly, researchers would rather look at the end results and presume that the findings got there according to the theory they are testing, as is the case with prospect theory.

\subsection{Prospect theory does not apply to real-world decisions}

A major limitation of prospect theory is that it is always presented as a choice between two prospects, whereas in the real world the decision is more likely to be whether or not to adopt a single prospect. This difference is vital because of the phenomenon known as preference reversal, as identified by Paul Slovic (e.g., 1995), a long-time colleague of Kahneman and Tversky who believed their account of decision-making was far too narrow. Preference reversal can occur when two different presentation conditions apply. One condition, known as single evaluation (SE), arises when a single prospect is being evaluated on its own as to whether or not to adopt it; and the other condition, known as joint evaluation (JE), arises when two or more prospects are being considered side-by-side, as in prospect theory, with a choice of one having to be made. The term "preference reversal" refers to the fact that the very same prospect that is accepted in an SE presentation can be rejected in a JE presentation; and vice versa. As an example of preference reversal, consider the two hypothetical environmental protection programs shown in Table 2 (Hsee, Loewenstein, Blount, \& Bazerman, 1999, p. 587). According to Hsee et al., Program $S$ is likely to be accepted in a single evaluation because of its very high effectiveness (80\% of the birds being saved). Program J, however, is likely to be accepted over Program S in a joint evaluation - the prospect theory situation - because the expected number of birds saved in Program J, 20\% of 50,000 or 10,000 birds saved, is larger than the $80 \%$ of 5,000 or only 4,000 birds saved in Program S. Only rarely in the real world would proposals be considered side-by-side in pairs as in prospect theory.

Table 2 about here

A second real-world limitation relates to the expected value formula $\mathrm{p} \times \mathrm{v}$, which computes the expected value of a prospect as the probability, p, of the outcome occurring multiplied by the judged value, v, of the outcome if it occurs. One difficulty arises with the "p" in the formula when applied to real-world decisions. In real-world decisions, the probability of success of a proposed course of action is always unclear and in most cases is left to a vague verbal description (see Juslin, Nilsson, \& Winman, 2009). But in prospect theory, one prospect is presented as certain, which can't possibly be true since a prospect is only a prediction and by definition a prediction cannot be made with certainty, while the other prospect is presented with an impossibly exact probability. The precise probabilities in Tversky and Kahneman’s (1981) 
“Asian disease problem” as discussed shortly, for example, would immediately raise suspicion that the problem is merely hypothetical.

The other difficulty relates to the " $v$ " in the expected value formula. In prospect theory's extension to social dilemmas the outcomes are always along one dimension, are simplistically binary, and are seemingly easy to evaluate - such as human life and death in the Asian disease problem and birds' life and death in Hsee et al.'s problem. In real-world social dilemmas, in contrast, the outcomes are always multiple, always involve a range of possible outcomes, and the outcomes are extremely difficult to place an exact monetary value on (Fischoff, Slovic, \& Lichtenstein, 1980). Life and death, for instance, the extreme gain and the extreme loss, are not the only two outcomes because the possibility of illness and resultant lower quality of life constitutes a mid-range outcome that can range widely in value. And in most societies young people's deaths are evaluated more negatively than adults' deaths, with the least value assigned to very old people's deaths (Robinson, Covey, Spencer, \& Loomes, 2010). Moreover, in the real world, proposed policy solutions have to be evaluated in light of their expected cost - a loss in prospect theory terms. Take the "birds" problem or the "Asian disease” problem as examples: the cost of each program is not given.

This last criticism of prospect theory may not be readily seen to apply to consumer decisions, but it does. It applies to what consumer behaviorists call "high involvement" or "high risk" decisions and also to low-risk decisions. High-involvement consumer decisions - such as buying a first home or buying a new car or, these days especially, choosing between the many alternative forms of healthcare - cannot in any way be accounted for by prospect theory. Firstly, there are usually more than two alternatives. Secondly, each alternative has multiple attributes not just one as in prospect theory, and these are a mix of positive and negative attributes that each carries a different weight - a weight that is likely to differ across various segments of consumers. Lastly, there are no certain outcomes, only probabilistic ones, so the choice between a certain prospect and a probabilistic prospect never arises. Even in low-risk choice situations where taking a shortcut such choosing "lowest price" or "my usual” is common, consumers do not go through anything like a prospect theory decision-making process.

\section{A CRITIQUE OF FRAMING}

“Framing,” Tversky and Kahneman’s (1981) concept, like prospect theory itself, can also be exposed as being unoriginal. Framing choices between prospects in terms of gains only or losses only is merely to use a one-sided presentation of information (see, e.g., Hovland, Janis, \& Kelley, 1953). Framing is therefore a further example of borrowing from psychology without acknowledgement. That the framing effect is unoriginal does not invalidate it, but in the next two sections it is shown that Kahneman and Tversky did not test framing properly and that subsequent tests of framing by other researchers have not been based on prospects as such. In the final section it is claimed that regardless of any evidence about whether it works or not, the tactic known as framing is unethical in most real-world situations.

\subsection{Tversky and Kahneman's test of framing was bungled and unconvincing}

Tversky and Kahneman (1981) tested the prospect theory version of framing in their famous experiment on the "Asian disease problem," which is reproduced in Table 3. Problem 1 
uses positive or gain-framing and Problem 2 uses negative or loss-framing. Separate groups of intelligent university students were given just one of these problems in a between-subjects design to prevent possible carryover effects. Firstly it should be realized that Tversky and Kahneman did not set out to test positive vs. negative framing; such a test would have been unnecessary according to prospect theory because the double weight given to a negative outcome would always favor negative framing. Rather, they set out to test an interaction hypothesis predicted only by prospect theory, namely that positive or gain-framed prospects, as in Problem 1, would be subject to the certainty effect for gains; whereas negative or loss-framed prospects, as in Problem 2, would be subject to the probability effect for losses.

Table 3 about here

Inspect Table 3 closely and you will see that Tversky and Kahneman turned out to be very poor experimenters. Firstly, it can be seen that in the gain-framed choice in Problem 1, where the certainty effect for gains was predicted, Program A, the certain prospect, is presented one-sided as a gain only (stating only the number of people who are expected to be saved, and leaving it open for the respondent to speculate about what happened to the rest). Program B, however, is presented two-sided as both a gain and a loss (referring to both lives saved and lives not saved). To represent consistent gain-framing, of course, Program B should have been described simply as a one-in-three chance that 600 people will be saved, without the mention of the probability of not being saved. Similarly, in the loss-framed choice in Problem 2, Program C is presented as a one-sided loss whereas Program D is presented two-sided as both a loss and a gain when, for consistent loss-framing, it should have been described only as a two-in-three chance of a loss. This fault in Tversky and Kahneman's experiment was exposed by Druckman (2001) who replicated the Asian disease experiment but added two-sided versions of each prospect. When presented two-sided, the certainty effect for gains and the probabilistic effect for losses were not found.

The second mistake that Tversky and Kahneman made in the Asian disease problem was to force a choice - "Which of the two programs would you favor?" Those respondents who mentally supplied the missing information and saw that the expected values of the two programs were equal were prevented from saying so - meaning that they would have to guess at what the experimenter was looking for and make a choice accordingly. Whether or not they guessed in favor of the experimenters' hypothesis - as they seemed to in Tversky and Kahneman's experiment - is beside the point. The point is that the Asian disease problem presentation prevents a rational decision from being made.

While the first two mistakes concern the internal validity of Tversky and Kahneman's experiment, the third mistake concerns its external validity or, in other words, its realism. In the Asian disease problem there are many elements that suggest that it is merely hypothetical: the problem contains very little information, the "scientific estimate[s] of the consequences" are obviously far too precise to be estimates, and also the whole exercise was administered by a professor in a classroom. The Asian disease problem therefore depends on respondents not seeing that the expected values are equal, or else seeing this and concluding that the professor is trying to trick them. The Asian disease problem - and other social dilemma framing problems like it - come across as hypothetical academic exercises and as such do not warrant serious consideration

\subsection{Subsequent framing experiments did not test prospect theory}


If you look up "Framing effect" on the Wikipedia website (2018) you will find several other experiments that correctly used one-sided presentations of both prospects - but with one important difference. All subsequent experiments skipped Tversky and Kahneman's idea of testing a certain gain against a probabilistic gain, and conversely a certain loss against a probabilistic loss. What the subsequent researchers did was drop the idea of probability altogether (the $\mathrm{p}$ in the $\mathrm{p} \times \mathrm{v}$ formula) and tested only a non-probabilistic positive frame against a non-probabilistic negative frame. In consumer behavior, for example, Donovan and Jalleh (1999) presented consumers with identical cuts of meat where one was labeled as "75\% lean" and the other as " $25 \%$ fat." These are not prospects but rather are stated facts. And, absent further information, they are equivalent facts with no rational basis to choose between them. This and all subsequent framing experiments tested only the positive vs. negative framing of factual claims.

Also, the only link to prospect theory in these subsequent framing experiments is that they rely on loss aversion which, as we said, is not an original prospect theory idea. Donovan and Jalleh's (1999) demonstration that consumers preferred meat labeled " $75 \%$ lean" over meat labeled " $25 \%$ fat," for instance, relies only on their aversion to the negatively described though technically equivalent product.

\subsection{Framing is unethical}

Positive framing and negative framing, to put it bluntly, rely on deception. They use a one-sided presentation - also known as lying by omission - and as such they are most at home in the world of "spin" - politics, personal selling, and advertising. Political speech, not everyone knows, is protected by law to allow lying in any form, omission or omission; unethical though this is, we the public cannot do anything about it. But what is the ethical situation in marketing? In personal selling, consumers are protected from one-sided presentations - lying by omission only by the ethics of the individual salesperson (which is why the "cooling-off period" was made law for other than routine purchases). In personal selling on the Internet via paid so-called influencers, however, there are obviously no ethical constraints and deceptively framed arguments are the norm.

Advertising, on the other hand, does offer consumers protection (via the FTC Act and the FDA Act in the U.S. and similar government regulations in most other countries) but only against marketers' omission of information about proven dangerous consequences.

Pharmaceutical product advertising, for example, must include disclosure of proven dangerous side effects, and increasingly food and beverage products are being required to disclose information about allegedly dangerous sugar content. If information about dangerous consequences is withheld, then there is little argument that one-sided presentation is unethical both morally because of the lying by omission and also from a utilitarian standpoint because of the dangers themselves. In advertising, this leaves one-sided presentation - or "framing" - as acceptable only when consumers are making a low-risk or "low involvement" product or service choice, where advertising messages must be kept short and consumers are presumed capable of detecting any harmless negatives about the product or service by trying it at low cost. This of course is positive framing.

It is a different story for negative framing. As Rossiter, Percy, and Bergkvist (2018) point out, most government social marketers are all too ready to adopt one-sided negative framing as a tactic to counteract consumer uptake of what they regard as harmful products and 
services. Whereas this tactic is perhaps justifiable by utilitarian ethics, it constitutes illegal deception and would be ruled out from a moral ethical standpoint.

\section{CONCLUSIONS}

Prospect theory and the framing effect are clever stories that seem to make intuitive sense to everybody. They even make sense to most academics - perhaps because prospect theory's inventors are highly respected researchers and perhaps because their article announcing the framing effect was published in the prestigious journal, Science. The present author argues in this article, however, that their acceptance is not justified. Briefly put: prospect theory is contrived and artificial, and framing, in vital situations at least, is unethical.

The present author would like to raise an issue that some may regard as ad hominem and therefore unfair, but which needs to be brought to light. This is the allegation that Kahneman borrowed most of his ideas from consumer behavior theorists. To buttress this allegation it may be seen that Kahneman's (2011) best-selling book titled Thinking Fast and Slow seems to borrow from marketer Herbert Krugman's (1972) idea of superficial low-involvement processing, which Krugman influentially contrasted with more careful high-involvement processing. Consumer behavior theorist Peter Wright (1975), too, proposed that choice behavior can be either heuristic or more thoughtful and did so years before Kahneman did, and Wright more usefully spelled out the information-processing mechanisms underlying both. Then, too, there was Petty and Cacioppo's (1983) distinction between peripheral and central processing that long predated Kahneman's book. Kahneman is not alone among economists in the borrowing game. Richard Thaler, originally a student and colleague of Kahneman and Tversky, who was awarded the Nobel Prize in Economics in 2017 for his work on decision making, admitted only half-jokingly to a reporter: "I basically have made a career stealing ideas from psychologists" (Luebsdorf \& Gauthier-Villars, 2017, p. 21). It could even be alleged that Thaler borrowed his central idea of "nudging" from the earlier work of Andrew Ehrenberg, who coined the term in marketing to describe the way he believed that advertising works (e.g., Barnard \& Ehrenberg, 1997). It must be said that consumer behaviorists - beginning most obviously with the often-called father of consumer behavior, John A. Howard (e.g., 1963, 1977) - have been much readier to acknowledge their debts to other disciplines than have the prospect theorists.

\section{REFERENCES}

Barnard, N., \& Ehrenberg, A. (1997). Advertising: Strongly persuasive or nudging? Journal of Advertising Research, 37(1), 21-32.

Baumeister, R.F., Bratslavsky, E., Finkenauer, C., \& Vohs, K.D. (2001). Bad is stronger than good. Review of General Psychology, 5(4), 323-370.

Bettman, J.R. (1970). Information processing models of consumer behavior. Journal of Marketing Research, 7(3), 370-376.

Domjan, M. (2018). The essentials of conditioning and learning. Fourth edition. Washington, DC: American Psychological Association. 
Donovan, R.J., \& Jalleh, G. (1999). Positively vs. negatively framed product attributes: The influence of involvement. Psychology \& Marketing, 16(7), 613-630.

Druckman, J. (2001). Evaluating framing effects. Journal of Economic Psychology, 22 (1), 96101.

Estes, W.K. (1944). An experimental study of punishment. Psychological Monographs, 57(263), $1-40$.

Fischoff, B., Slovic, P., \& Lichtenstein, S. (1980). Knowing what you want: Measuring labile values. In T.S. Walston (Ed.), Cognitive processes in choice and decision behavior. Hillsdale, NJ: Lawrence Erlbaum Associates (pp. 117-141).

Hovland, C.I., Janis, I.L., \& Kelley, H.H. (1953), Communication and persuasion: Psychological studies of opinion change. New Haven, CT: Yale University Press.

Howard, J.A. (1963). Marketing: Executive and buyer behavior. New York, NY: Columbia University Press.

Howard, J.A. (1977). Consumer behavior: Application of theory. New York, NY: McGraw-Hill.

Hsee, C.K., Loewenstein, G.F., Blount, S., \& Bazerman, M.H. (1999). Preference reversals between joint and separate evaluations of options: A review and theoretical analysis. Psychological Bulletin, 125(5), 576-590.

Janiszewski, C., Silk, T., \& Cook, A.D.J. (2003). Different scales for different frames: The role of subjective scales and experience in explaining attribute-framing effects. Journal of Consumer Research, 30(3), 311-325.

Johnson, E.J., Shulte-Mecklenbeck, M., \& Willemsen, M.C. (2008). Process models deserve process data: Comment on Brandstätter, Gigerenzer, and Hertwig (2006). Psychological Review, 115(1), 263-273.

Juslin, P., Nilsson, H. \& Winman, A. (2009). Probability theory: Not the very guide of life. Psychological Review, 116(4), 856-874.

Kahneman, D. (2011). Thinking fast and slow. London, U.K.: Allen Lane.

Kahneman, D., \& Tversky, A. (1979). Prospect theory: An analysis of decision under risk. Econometrica, 47(2), 263-291.

Krugman, H.E. (1972). Why three exposures may be enough. Journal of Advertising Research, 12(6), 11-14.

Luebsdorf, B., \& Gauthier-Villars, D. (2017). Nobel economist focuses on irrational. The Australian (reproduced from The Wall Street Journal), October 11, p. 21.

March, D.S., Gaertner, L., \& Olson, M.A. (2017). In harm’s way: On preferential response to threatening stimuli. Personality and Social Psychology Bulletin, 43(11), 1519-1529.

Mittal, B., Holbrook, M.B., Beatty, S., Raghubir, P., \& Woodside, A.G. (2008). Consumer behavior. Cincinnati, $\mathrm{OH}$ : Open Mentis. 
Morales, A.C., Amir, O., \& Lee, L. (2017). Keeping it real in experimental research understanding when, where, and how to enhance realism and measure consumer behavior. Journal of Consumer Research, 44(2), 465-476.

Petty, R.E., \& Cacioppo, J.T. (1983). Central and peripheral routes to persuasion: Application to advertising. In L. Percy \& A.G. Woodside (Eds.), Advertising and consumer psychology. Lexington, MA: Heath (pp. 3-23).

Robinson, A., Covey, J., Spencer, A., \& Loomes, G. (2010). Are some deaths worse than others? The effect of 'labelling' on people’s perceptions. Journal of Economic Psychology, 31(3), 444-455.

Rossiter, J.R., Percy, L., \& Bergkvist, L. (2018). Marketing communications: Objectives, strategy, tactics. London: Sage.

Russo, J.E., Johnson, E.J., \& Stephens, D.L. (1989). The validity of verbal protocols. Memory \& Cognition, 17(6), 759-769.

Siegler, R., \& Lortie-Forgues, H. (2017). Hard lessons: Why rational number arithmetic is so difficult for so many people. Current Directions in Psychological Science, 26(4), 346-351.

Simon, H.A. (1957). Models of man. New York, NY: Wiley.

Slovic, P. (1995). The construction of preference. American Psychologist, 50(5), 364-371.

Tversky, A., \& Kahneman, D. (1981). The framing of decisions and the psychology of choice. Science, 211(January 30), 453-458.

Tversky, A., \& Kahneman, D. (1992). Advances in prospect theory: Cumulative representation of uncertainty. Journal of Risk and Uncertainty, 5(4), 297-323.

Vaish, A., Grossmann, T., \& Woodward, A. (2008). Not all emotions are created equal: The negativity bias in social-emotional development. Psychological Bulletin, 134(3), 383-403.

Wikipedia (2017a). Health literacy. Last modified March 30, 2017.

Wikipedia (2017b). Numeracy. Last Modified April 8, 2017.

Wikipedia (2018). Framing effect (psychology). Last modified August 9, 2018.

Wright, P.L. (1975). Consumer choice strategies: Simplifying vs. optimizing. Journal of Marketing Research, 12(1), 60-67. 
TABLE 1 The first three prospect theory problems used by Kahneman and Tversky in their 1979 article

Problem 1: Choose between
(A) $\$ 2,500$ with probability .33, $\$ 2,400$ with probability .66 ,
(B) $\$ 2,400$ with certainty
$\$ 0$ with probability
.01

Problem 2: Choose between

$\begin{array}{ll}\text { (C) } \$ 2,500 \text { with probability } & .33 \text {, } \\ \$ 0 \text { with probability } & .67\end{array}$

(D) $\$ 2,400$ with probability .34 , \$0 with probability $\quad .66$

Problem 3: Choose between
(E) $(\$ 4,000, .80)$
(F) $(\$ 3,000)$ 
TABLE 2 Prospect theory problem used by Hsee et al. (1999) to illustrate joint vs. single evaluations

Program $\mathrm{S}$ is designed to save birds in a forest where there are 5,000 endangered birds; it can save $80 \%$ of these birds.

Program $\mathrm{J}$ is designed to save birds in a forest where there are 50,000 endangered birds; it can save $20 \%$ of these birds. 
TABLE 3 Tversky and Kahneman’s (1981) “Asian disease problem”

Imagine that the U.S. is preparing for the outbreak of an unusual Asian disease, which is expected to kill 600 people. Two alternative programs to combat the disease have been proposed. Assume that the exact scientific estimate of the consequences of the programs are as follows:

\section{Problem 1 (gain frame)}

If Program A is adopted, 200 people will be saved.

If Program B is adopted, there is a 1/3 probability that 600 people will be saved, and 2/3 probability that no people will be saved.

Which of the two programs would you favor?

Problem 2 (loss frame)

If Program C is adopted 400 people will die.

If Program $D$ is adopted there is $1 / 3$ probability that nobody will die, and 2/3 probability that 600 people will die.

Which of the two programs would you favor? 